Results Data was collected from a large range of health professionals working with palliative care patients. It was found that approximately $34 \%$ of respondents were not aware of any oral care guidelines for palliative care patients. Those that did were mostly aware of the NICE guidelines.

There was variation between all respondents as to what treatment was routinely given for various oral conditions. Some practices restricted in certain trusts were shown to be used elsewhere, for example foam swab use (70\%), which is not routinely recommended by dental professionals.

Although the majority of respondents reported their patients have personalised oral care plans in place, $43 \%$ do not.

Conclusions Clearer and more concise guidelines for oral care in palliative care patients is needed to ensure staff are able to offer the same level of evidence-based care consistently across the UK. The importance of oral care plans for these patients should be promoted, to ensure patients have continuity of care.

\section{PATTERNS OF GENERAL PRACTICE PRESCRIBING IN THE LAST YEAR OF LIFE}

${ }^{1}$ Amelia Harshfield, ${ }^{2}$ Rupert Payne, ${ }^{1}$ Stephen Barclay. 'University of Cambridge; ${ }^{2}$ University of Bristol

\subsection{6/bmispcare-2018-ASPabstracts. 120}

Background Little is known about patterns of prescribing in the last year of life in primary care.

Methods Recently completed analysis of UK Clinical Practice Research Datalink (CPRD), a large database extracted from GP records that is representative of the UK population. Prescribing data for the last 12 months of life were extracted from 118571 patients $^{6}$ GP records who died between September 2010 and August 2015. Two clinicians used British National Formulary codes to identify eight palliative care drug categories: antiemetics, anti-secretory, benzodiazepines, steroids, strong injectable opioids, strong patch opioids, strong enteral opioids, and weak oral opioids. The percentage of patients prescribed each medications was calculated at weekly intervals during the year before death, further stratified by cause of death and age at death. Random effects logistic regression models were run adjusted for age-group, sex, and cause of death.

Results Levels of prescribing significantly increased for all drugs at time of death compared with one year before death (with the exception of weak oral opioids and steroids where results were inconsistent across ages, genders, and causes of death). The largest increase was for $90+$ year old male patients prescribed strong injectable opioids (OR: 21032, 95\% CI: 3499 to 12641) and the greatest decrease for females prescribed steroids who died of external causes (OR: 0.52, 95\% CI: 0.34 to 0.70 ). Patients who died of cancer generally showed the most marked increase in prescribing towards the end of life compared with other causes of death.

Conclusions Primary care patterns of prescribing in the last year of life has not been previously investigated. The findings of this recently completed study of a large nationally-representative dataset reveal increasing GP prescribing in response to the rising symptom burden of all patient groups as death approached. The implications for clinical practice and future research will be discussed.
94 GUIDELINE DEVELOPMENT FOR THE MANAGEMENT OF AGITATION IN THE LAST WEEKS OF LIFE

Kate Nolan, Helen Bonwick, Claire Robinson, Mark Mills, A Griffiths, P Shepherd, N Shah. Marie Curie Hospice Liverpool

\subsection{6/bmjspcare-2018-ASPabstracts.121}

Background Agitation is a distressing and common symptom at the end of life; despite this the evidence for the management of this symptom is poor.

Aim

- Audit clinical practice around management of terminal agitation with patients and healthcare professionals (HCPs) against regional standards.

- Use audit outcomes to update regional standards and guidelines

\section{Method}

- Systematic literature review examining the evidence base.

- Survey of HCPs working in specialist palliative care.

- Retrospective case note review of patients with a diagnosis of terminal agitation receiving specialist palliative care in hospital, hospice or community settings.

Results Below is a summary from 185 responses from 11 different healthcare settings in the Merseyside area from retrospective case note review:

- Hospice 54.5\%, Hospital 29.7\%, Home 11.8\%, other including Nursing homes 3\%.

- Main reversible causes documented included: pain; breathlessness: constipation and urinary retention.

- $94 \%$ of patients had medications reviewed.

- Non-pharmacological interventions formed part of the overall management plan.

- $82 \%$ of patients had psychological and spiritual support offered to the patient and or family.

- First line pharmacological intervention is Midazolam, Levomepromazine is second line.

- In 92\% of cases a Syringe driver (CSCI) was used.

- Majority of deaths occurred in 3 days or less

- Communication with patient and family formed a key theme. At the time of death:

- Midazolam prescribed in 146 cases (mean $26 \mathrm{mg}$ - range 0$60 \mathrm{mg}$ ).

- Levomepromazine prescribed in 61 cases (Mean $56.8 \mathrm{mg}-$ range $5-250 \mathrm{mg}$ ).

- Haloperidol 25 cases (Mean $3.5 \mathrm{mg}$ - range 1-8 mg).

- Phenobarbital 9 cases ( Mean 922 mg - range 200-1200 mg).

Conclusion This Audit revealed the challenges and wide variation in practice with regards to management of terminal agitation. These findings have informed an update of the regional palliative care guidelines.

\section{THE 'SUPPORT OF CARE CYCLE': INTEGRATING ETHICS INTO HEALTHCARE PROFESSIONAL SUPPORT AND DEVELOPMENT IN HOSPICES}

Craig Gannon. Princess Alice Hospice

10.1136/bmjspcare-2018-ASPabstracts. 122

Background High-quality hospice care is dependent on an expert caring and resilient workforce who can cope with the 